\title{
Investigation of Mechanical Properties of Twin Wire Arc Repair of Cast Iron Components
}

\author{
K. DePalma ${ }^{1}$ M. Walluk ${ }^{1}$ L. P. Martin ${ }^{1} \cdot$ K. Sisak ${ }^{1}$
}

Submitted: 16 August 2021/in revised form: 5 November 2021/Accepted: 6 December 2021/Published online: 3 January 2022 (C) ASM International 2021

\begin{abstract}
Twin wire arc is a commonly used thermal spray technology for application of steel coatings to cast iron components. Hardness and adhesion strength are critical properties of such coatings, and significant research is available reporting these properties. However, the lamellar structure of the coatings and residual stresses induced during the coating process leads to significantly different behavior in bending applications than in purely tensile applications which are evaluated by the standard adhesion test. In addition, microstructural features that are controlled by certain process parameters during deposition of the coating can have a significant effect on these properties. This work relates the hardness, adhesion strength, and wear resistance to the coating microstructure and assesses the related bending strength and failure mode. Comparisons between bend tests and pull-off adhesion tests show significant differences to consider when designing a twin wire arc coating.
\end{abstract}

Keywords feedstock, adhesion testing $\cdot$ processing, stainless steel · properties, elastic modulus $\cdot$ properties . testing, abrasive wear $\cdot$ testing, three point bending $\cdot$ wire arc spray

This article is an invited paper selected from presentations at the 2021 International Thermal Spray Conference, ITSC2021, that was held virtually May 25-28, 2021 due to travel restrictions related to the coronavirus (COVID-19) pandemic. It has been expanded from the original presentation.

\section{K. DePalma}

kpdgis@ rit.edu

1 Golisano Institute for Sustainability, Rochester Institute of Technology, Rochester, NY, USA

\section{Introduction}

Remanufacturing is the process of restoring a worn or damaged product to its original condition. Remanufacturing may take many forms depending on the product of interest, but a common application is to repair surfaces that have been worn, cracked, or corroded. In these applications, a common strategy is to machine away the damaged surface and use an additive surface coating technology to rebuild the lost material. All repairs must perform as well or better than the original design, making it critical to understand the mechanical performance of the repair.

Twin wire arc (TWA) is a thermal spray process with the ability to deposit a wide range of surface coating materials at high deposition rates and reasonably low cost, making it an attractive option for remanufacturing. In the TWA process, a pair of wires is fed into a spray nozzle and a voltage difference is applied between the wires. The voltage differential creates an arc that melts the wire tips, and a stream of compressed gas, most commonly air, atomizes the molten metal and accelerates it toward the substrate surface. The resultant droplets are formed at temperatures upward of $5000{ }^{\circ} \mathrm{C}$ and can be accelerated to velocities up to $300 \mathrm{~m} / \mathrm{s}$ (Ref 1). The droplets cool and slow as they travel from the spray nozzle to the substrate. As a result, the distance to the substrate, referred to as standoff distance or SOD, and the atomizing gas pressure have a strong effect on the final microstructure. Finally, the spray gun is traversed across the substrate surface, to provide even coverage of the area to be coated or repaired.

The TWA process has been used to successfully deposit coatings of steels ( $\operatorname{Ref} 2)$, aluminum (Ref 3$)$, aluminum alloys (Ref 4), nickel alloys (Ref 5), and Inconel (Ref 6) onto a similar family of substrate metals. During the coating operation, there are five key processing parameters 
that can be modified to change the properties of the deposited coating: arc voltage, arc current, SOD, traverse speed, and atomizing gas pressure. Understanding the interdependency between these process parameters and the ultimate mechanical properties of the coating, including strength, elastic modulus, and fatigue resistance, is critical to successful implementation into remanufacturing applications. However, these mechanical properties are tied to both the microstructure and the residual stresses induced by the coating process (Ref 7). In addition, effective coating performance requires connectivity to the substrate structure through strong adhesion, and traditional methods of characterizing coatings are not always effective at assessing the capability of such structurally integrated systems (Ref 8). As a result, the interaction between process parameters and coating properties continues to be a subject of active research (Ref 9, 10), and Smith, et al., recently concluded that a "critical aspect" of leveraging TWA, and other related methods, to achieve resource and process sustainability "is through in-depth characterization and evaluation of these non-idealized composite systems" (Ref 8).

Because coating properties are intrinsically dependent upon microstructure, the impact of process parameters on the microstructure of thermal spray coatings has been reported upon for a variety of material systems (Ref $1,10-12,20)$. A significant aspect of the prior work was to identify the mechanisms by which the observed microstructures arise, and to elucidate the interactions between process conditions and microstructure. As a result, it is understood that thermal spray coatings are formed by the successive impact of molten droplets upon the surface, where the impacts of individual droplets are referred to as 'splats.' At least two distinct mechanisms occur during the formation of a splat: the droplet flattens out, and some fraction of the material splashes radially. The relative extent to which these processes occur is dependent on the droplet size, velocity (at the surface), temperature, and oxide content (Ref 11). In general, increasing the gas pressure decreases the droplet size and temperature and increases the velocity and oxide content. In contrast, increasing the standoff distance has no effect on the droplet size, decreases the temperature and velocity at impact, and increases the oxide content.

Significant effort has been contributed by researchers to evaluate the relationships between the above microstructural effects and the associated effects on the mechanical properties of TWA coatings. Jandin et al. found that the hardness of a high carbon steel coating increased with increasing gas flow rate when the accelerating gas was air and correlated the effect with the oxide content (Ref 12). The opposite was true when the gas was nitrogen, which was attributed to decreased porosity in the absence of the hard oxide phase. This result was confirmed by Gedzevicus et al., in a later study (Ref 1). Planche et al. studied the relationship between spray parameters, coating microstructure, and coating hardness, with similar findings as Jandin et al., but with the additional finding that porosity decreases with increasing gas flow rate due to greater flattening of the spray droplets (Ref 11). Fitriyana et al. also found that decreasing the standoff distance or compressed air pressure increased the hardness and adhesive strength for coatings of a FeCrBSiMn steel on 304 stainless steel (Ref 10) and attributed the improvements to the production of thinner coatings with less porosity.

Determination of the in-plane strength and elastic modulus of a TWA coating generally relies upon measurements performed on the coating/substrate system, followed by application of numerical analysis to differentiate the contribution of each constituent. The coating generally cannot be analyzed independently of the substrate due to physical limitations to the maximum achievable coating thickness, which occur due to the buildup of residual stresses during deposition. Jandin et al. used a cantilever beam method to measure the elastic modulus of high carbon steel coatings and found that the elastic modulus has a parabolic relationship with gas flow rate, increasing up to a maximum then decreasing at higher air flows. The elastic modulus of a 1080 steel coating was reported to be $100 \pm 10$ GPa, approximately half of the elastic modulus of bulk 1080 steel. (Ref 12). Leither et al. evaluated a 3-point bend method and a nano-indentation method to determine that the elastic modulus of a TWA sprayed Inconel 625 coating was $30 \%$ of the elastic modulus of bulk Inconel 625 (Ref 13). These prior investigations highlight the need for a better understanding of the coating properties required to properly design for applications requiring load bearing or resistance to bending.

In order for TWA to repair damaged components successfully, enabling extended post-remanufacturing lifetimes requires prior understanding of both the as-sprayed mechanical properties of the repair material and the interaction with the substrate material. This need for improved understanding of the mechanical performance of thermal spray coatings was discussed by Burkle et al. who used 3 -point bend testing to gather data on the yield strength, ultimate strength, and elastic modulus of aluminum alloy coatings. The reported elastic moduli were within the expected values for bulk material of the same composition, except when the coatings contained excessive levels of oxide inclusions. Burkle et al. also noted that the elastic modulus of the coating is dependent on the spray parameters, and that the performance of the coating is closely tied to optimization of the elastic modulus (Ref 4). Similarly, Rodriguez et al. note in their study of abrasive wear of TWA coatings that understanding the relationships 
between coating microstructure and wear resistance is important when designing a coating process (Ref 14).

This paper reports results from a parametric study of standoff distance and gas pressure on TWA coatings of 420 stainless steel on ductile cast iron substrates. The effects of these parameters on the microstructure, hardness, and adhesive strength of the coatings are presented and discussed. Additionally, bend testing was performed on selected samples to determine the in-plane strength and elastic modulus, and the failure modes were assessed by metallographic methods. An abrasive wear test was also performed on selected samples to relate the microstructure to wear resistance.

\section{Methods and Materials}

\section{Materials}

For this study, 80-55-06 ductile cast iron substrates, provided by Dura-Bar ${ }^{1}$, were coated with 420 stainless steel provided by Polymet $^{2}$ under the trade name PMET 720. The nominal compositions of the ductile cast iron and 420 stainless steel wire are given in Table 1. The diameter of the 420 stainless steel wire was $1.6 \mathrm{~mm}$. Round substrates with a diameter of $54 \mathrm{~mm}$ and thickness of $13 \mathrm{~mm}$ were coated for adhesion and hardness testing (Fig. 1). Rectangular substrates with a width of $30 \mathrm{~mm}$, length of $125 \mathrm{~mm}$, and thickness $9.5 \mathrm{~mm}$ were coated for 3-point bend testing and had a similar mass to the round specimens. All test coupons were saw cut from bar stock and milled flat prior to coating.

\section{Coating Procedure}

In order to roughen the surface prior to coating to improve bonding, the substrates were grit blasted with 36 grit $\mathrm{Al}_{2} \mathrm{O}_{3}$ to achieve a surface roughness of at least $6 \mu \mathrm{m} \mathrm{R}_{\mathrm{a}}$, as measured with a Starrett ${ }^{3}$ SR-100 portable profilometer. Dust from the grit blast was removed using compressed air, and the samples were wiped with isopropyl alcohol. Samples were coated within one hour from the grit blasting procedure to minimize the formation of an oxide layer on the surface (Ref 15).

A Thermach ${ }^{4}$ AT-400 TWA system was used for the coating process, with compressed air as the atomizing gas for all experiments. This system allows for control of five main spray parameters: arc voltage, arc current (which also

\footnotetext{
${ }^{1}$ Dura-Bar. Woodstock, IL, USA.

${ }^{2}$ Polymet Corporation, Chester, OH, USA.

${ }^{3}$ L. S. Starrett Company, Athol, MA, USA.

${ }^{4}$ Thermach, Appleton, WI, USA.
}

governs wire feed rate), atomizing gas pressure, SOD, and traverse speed. In this study, the gas pressure and SOD were varied from 550 to $825 \mathrm{kPa}$ and $75-150 \mathrm{~mm}$, see Table 2, while all other spray parameters were held constant: arc voltage $-30 \mathrm{~V}$, arc current $-80 \mathrm{~A}$, and traverse speed $-150 \mathrm{~mm} / \mathrm{s}$. The baseline parameters (Group 1) were derived from manufacturer recommendations. It is well established that increasing air pressure produces coatings with greater oxide content and higher hardness (Ref 12). This study increased the air pressure by $50 \%$ to replicate this effect and understand any potential tradeoffs associated with higher pressure. It is also established by past research that reduction of SOD is generally linked to a denser, lower porosity coating (Ref 10). This study reduced the SOD from the manufacturer recommendation to attempt to reduce coating porosity. The spray gun was affixed to an $\mathrm{ABB}^{5}$ IRB-1600 industrial robot, which was used to control standoff distance and traverse rate. To improve coating homogeneity, the spray parameters were selected to produce coatings comprised of 10 layers, each approximately $120 \mu \mathrm{m}$ thick. Each consecutive layer was sprayed immediately following the preceding layer.

\section{Test Methods}

Adhesion testing was performed in accordance with ASTM D4541 (Ref 16) using a DeFelsko PosiTest AT-M ${ }^{6}$ handheld pull-test device to measure the load to failure. Samples for adhesion testing were coated with $1.2 \mathrm{~mm}$ of the 420 stainless steel. Because the surfaces of the as-sprayed coatings were too rough to allow reliable adhesive bonding to the test coupon (dolly), Fig. 1, the procedure was modified by sanding the top surface of the coatings to 220 grit to improve the bonding and reduce the likelihood of an epoxy failure. A small channel was milled around the test sites to control the failure area, and the test dollies were bonded in place using Solvay ${ }^{7}$ FM1000 epoxy. As shown in Fig. 1, each coupon was sized to permit two adhesion tests. Two replicate coupons were fabricated at each test condition. After each test, the dolly was inspected to verify that the sample failed at the coating/substrate interface, and to measure the failure area in order to accurately calculate the stress at failure.

After adhesion testing, the test coupons were crosssectioned, mounted, and polished for metallographic inspection. Samples were polished using a Buehler ${ }^{8}$ AutoMet 250 polishing system. Polishing steps consisted of grinding with 240 and 600 grit $\mathrm{SiC}$, and polishing using 9,

\footnotetext{
5 ABB Ltd, Zurich, SZ.

${ }^{6}$ DeFelsko Corporation, Ogdensburg, NY, USA.

${ }^{7}$ Solvay S.A, Brussels, BE.

${ }^{8}$ Buehler Ltd, Lake Bluff, IL, USA.
} 
Table 1 Nominal chemical composition of substrate and feedstock. Values are maxima unless stated as a range

\begin{tabular}{lccccccccccccc}
\hline & $\mathrm{Fe}$ & $\mathrm{C}$ & \multicolumn{1}{c}{$\mathrm{Cr}$} & $\mathrm{Si}$ & $\mathrm{Mn}$ & $\mathrm{Ni}$ & $\mathrm{Mo}$ & $\mathrm{P}$ & $\mathrm{S}$ & $\mathrm{Cu}$ & $\mathrm{Al}$ & $\mathrm{Sn}$ \\
\hline Ductile Iron & $\mathrm{Bal}$ & $3.50-3.90$ & $\ldots$ & $2.25-3.00$ & $0.15-0.35$ & $\ldots$ & $\ldots$ & 0.05 & 0.025 & $\ldots$ & $\ldots$ & $\ldots$ \\
$420 \mathrm{ss}$ & $\mathrm{Bal}$. & $0.30-0.40$ & $12.00-14.00$ & 1.0 & 1.00 & 0.5 & 0.5 & 0.04 & 0.03 & 0.5 & 0.15 & 0.05 \\
\hline
\end{tabular}

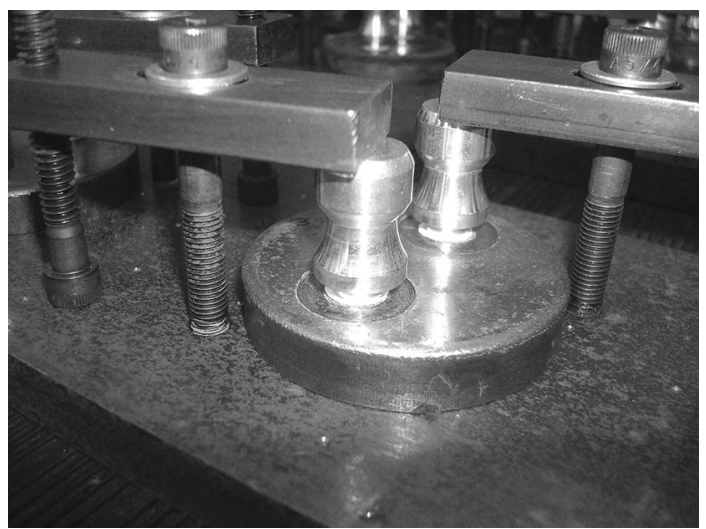

Fig. 1 Adhesion sample geometry and test preparation

Table 2 Spray parameter groups

\begin{tabular}{lcc}
\hline Group \# & Air Pressure, $\mathrm{kPa}$ & $\mathrm{SOD}, \mathrm{mm}$ \\
\hline 1 & 550 & 150 \\
2 & 825 & 150 \\
3 & 550 & 75 \\
4 & 825 & 75 \\
\hline
\end{tabular}

3, and $1 \mu \mathrm{m}$ diamond suspensions. Microstructures were imaged using light optical microscopy (LOM). Porosity was determined from image analysis of LOM images following "Test Method B" from ASTM E2109 (Ref 17). Four images of each sample at 200x were measured for porosity, leading to a total of eight measurements per spray condition. Oxidation measurements were not pursued, as oxidation measurements of TWA coatings have been reported and discussed in previous studies (Ref 12). Hardness testing was performed on the coatings using both the Vickers and Rockwell C methods. Vickers micro-indentation hardness testing was performed on the metallographic cross sections at three depths: near the substrate/coating interface, in the middle of the coating, and near the surface. The testing used a $200 \mathrm{~g}$ load and was performed on a LECO $^{9}$ automated micro-indentation hardness tester. The average indent size at this load was 30 $\mu \mathrm{m}$, or $2.5 \%$ of the coating thickness. Each specimen was tested a total of 24 times, eight tests at each depth.

${ }^{9}$ LECO Corporation, St. Joseph, MI, USA.
Rockwell C hardness was measured normal to the coating on the sanded top surfaces and followed testing parameters from ASTM E18 (Ref 18). Each specimen was tested four times, yielding a total of eight hardness measurements per spray condition.

Bend testing was performed using a 3-point bend fixture on an Instron ${ }^{10}$ universal test system equipped with an Instron 2527 load cell. A schematic of the test configuration is shown in Fig. 2. In all cases, the sample was tested with the coated side in tension and the uncoated side in compression. The samples for bend testing were coated with approximately $1.5 \mathrm{~mm}$ of the 420 stainless steel. Selected samples were instrumented with a strain gauge on the coating surface. All bend tests were force controlled at a constant load rate of $500 \mathrm{~N} / \mathrm{min}$.

Wear testing utilized a loop abrasion test method, see Fig. 3, performed in accordance with ASTM G174 Option $\mathrm{C}(\operatorname{Ref} 19)^{11}$. Prior to testing, samples were cut to a size of $32 \mathrm{~mm} \times 8 \mathrm{~mm} \times 4 \mathrm{~mm}$ using wire EDM, and the coated faces were polished to a roughness of approximately 0.2 $\mu \mathrm{m}$. The abrasive medium was $30 \mu \mathrm{m}$ aluminum oxide adhered to a polyester tape. The applied load was $100 \mathrm{~g}$, and the test was run for a total of 75 belt passes at 100 RPM. Four replicate samples were tested of the uncoated substrate, and of spray conditions 1,2 , and 3 , leading to a total of 16 tests. Wear resistance is inversely related to the volume loss during the test. Because the sample engages with the abrasive while pressed into a round shaft, the wear scar is a cylindrical segment with a volume which depends only on the width of the scar, the shaft diameter, and the width of the sample. The volume loss is calculated by

$V_{\text {scar }}=\frac{D^{2} t}{8}\left[2 \sin ^{-1}\left(\frac{b}{D}\right)-\sin \left(2 \sin ^{-1}\left(\frac{b}{D}\right)\right)\right]$

where $D=$ the shaft diameter $(17 \mathrm{~mm}), t=$ the sample width $(8 \mathrm{~mm})$, and $b=$ the scar width (measured using LOM). Note that, the sample width refers to the length of the initial line contact between the sample and abrasive belt.

\footnotetext{
${ }^{10}$ Instron, Norwood, MA, USA.

11 Bud Labs, 3145 Dewey Ave., Rochester, NY, USA.
} 


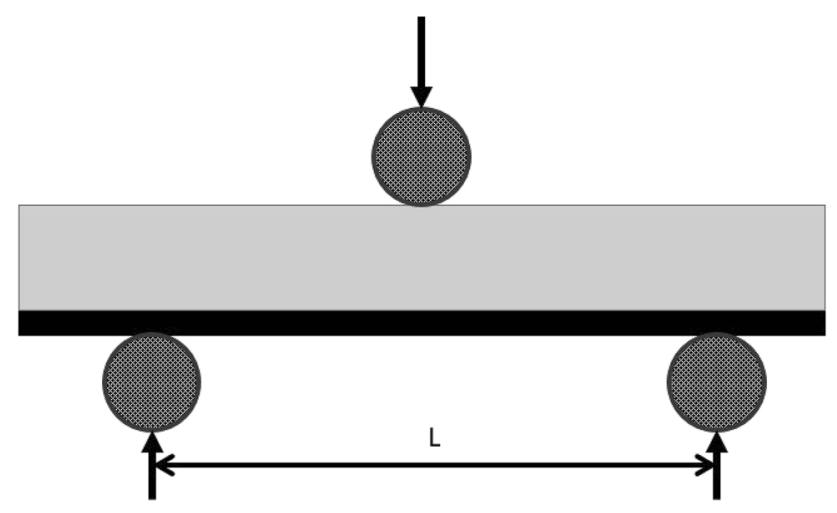

Fig. 2 3-point bend test setup where $\mathrm{L}=84 \mathrm{~mm}$

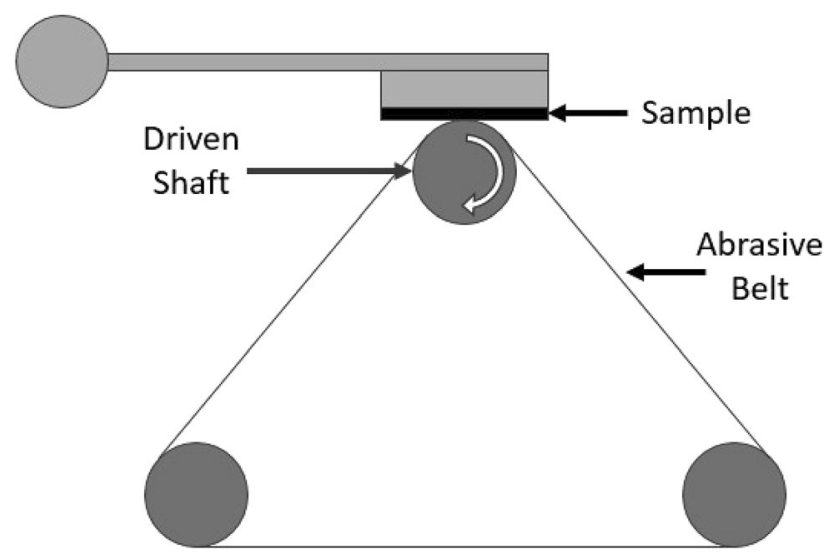

Fig. 3 Abrasive wear test apparatus

\section{Results and Discussion}

\section{Adhesion Testing}

Adhesion testing was performed on four groups of samples to investigate the effects of air pressure and standoff distance (SOD), with all other parameters held constant. The baseline condition of $550 \mathrm{kPa}$ and $150 \mathrm{~mm}$ SOD (Group 1) produced consistent coatings with strengths of approximately $30 \mathrm{MPa}$, see Fig. 4. Increasing the air pressure (Group 2) or reducing SOD (Group 3) increased the average adhesive strength by $8 \%$ and $15 \%$, respectively. In contrast, the combination of increased air pressure and decreased SOD led to disbonded coatings with near zero adhesive strength (Group 4). The error bars in Fig. 4 show the minimum and maximum recorded values, indicating that while the average strengths were higher in Groups 2 and 3, Group 1 displayed the most consistent results. All samples exhibited purely adhesive failures. Note that, because Group 4 failed to consistently produce a wellbonded coating, no further testing was performed on that parameter set.

\section{Metallography and Hardness}

Selected specimens were cross-sectioned, mounted, polished, and imaged to evaluate the microstructural differences caused by the modified spray parameters. Porosity, voids, oxides, and pre-solidified droplets were all features of interest. LOM images from Groups 1, 2, and 3 are shown in Fig. 5.

Figure 5(a) shows a typical TWA microstructure from Group 1, with a uniformly distributed layered (lamellar) structure of light and dark gray phases, and intermittent isolated residual porosity (black phase). Rodriguez et al. used EDS to determine that the light and dark gray phases present in TWA microstructure are alloy and oxide phases, respectively (Ref 14 ). The top of the ductile iron substrate is also visible at the bottom of the image. In TWA, there is no significant melting in the substrate, and no resultant dilution zone at the coating interface. Fig. 5(b) shows a similar structure from Group 2, but with evidence of increased oxide and decreased porosity. In addition, the structure contains distributed localized colonies of oxide that are larger than any visible oxide features in Fig. 5(a) (red arrows). Fig. 5(c) shows a significantly different structure in Group 3, with higher porosity and localized regions of low oxide content separated by extended oxide-laden structures that propagate through multiple layers of the coating (red ellipse). Image analysis was used to calculate the mean porosity of Groups 1,2 , and 3 to be approximately 2.51 .2 , and $1.8 \%$, respectively. The standard deviations of the porosity measurements were 0.9 , 0.2 , and $0.4 \%$, respectively.

Figures 6 and 7 show higher-magnification images of the microstructures from the same samples shown in Fig. 5. Figures 6(a) and 7(a) show the microstructure of Group 1 to consist of a layered structure of metallic alloy and oxide, with porosity concentrated around the oxide inclusions and limited in size to less than $25 \mu \mathrm{m}$. In addition, pre-solidified droplets, resulting from droplets that solidified prior to reaching the substrate, can be seen embedded into the coating as round alloy inclusions. Figures 6(b) and 7(b) show the Group 2 microstructure to be similar to Group 1, but with fewer pores, which is consistent with the image analysis presented above, as well as higher oxide content and finer lamellae. Finally, the remaining images show two distinct microstructures in the Group 3 coatings. The first, shown in Figs. 6(c) and 7c, has low oxide content, low porosity, and small pore size less than $20 \mu \mathrm{m}$. The second, shown in Figs. 6(d) and 7(d), has high oxide content and large pores of up to more than $40 \mu \mathrm{m}$. As noted above, these high-oxide regions in the Group 3 microstructure form into columnar structures that propagate through multiple layers. This phenomenon has been attributed to the entrapment of liquid oxide splatter by 


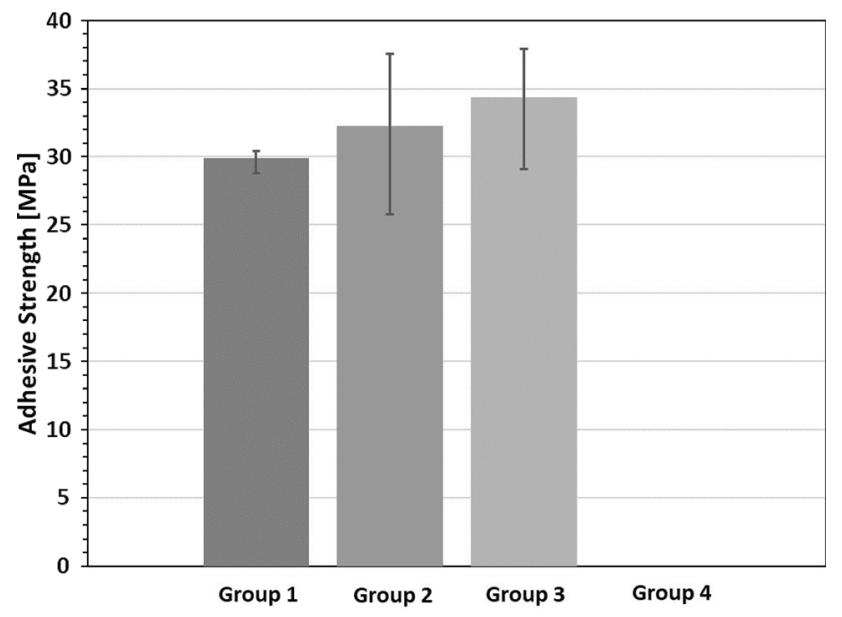

Fig. 4 Adhesion test results. Error bars indicate the minimum and maximum values observed
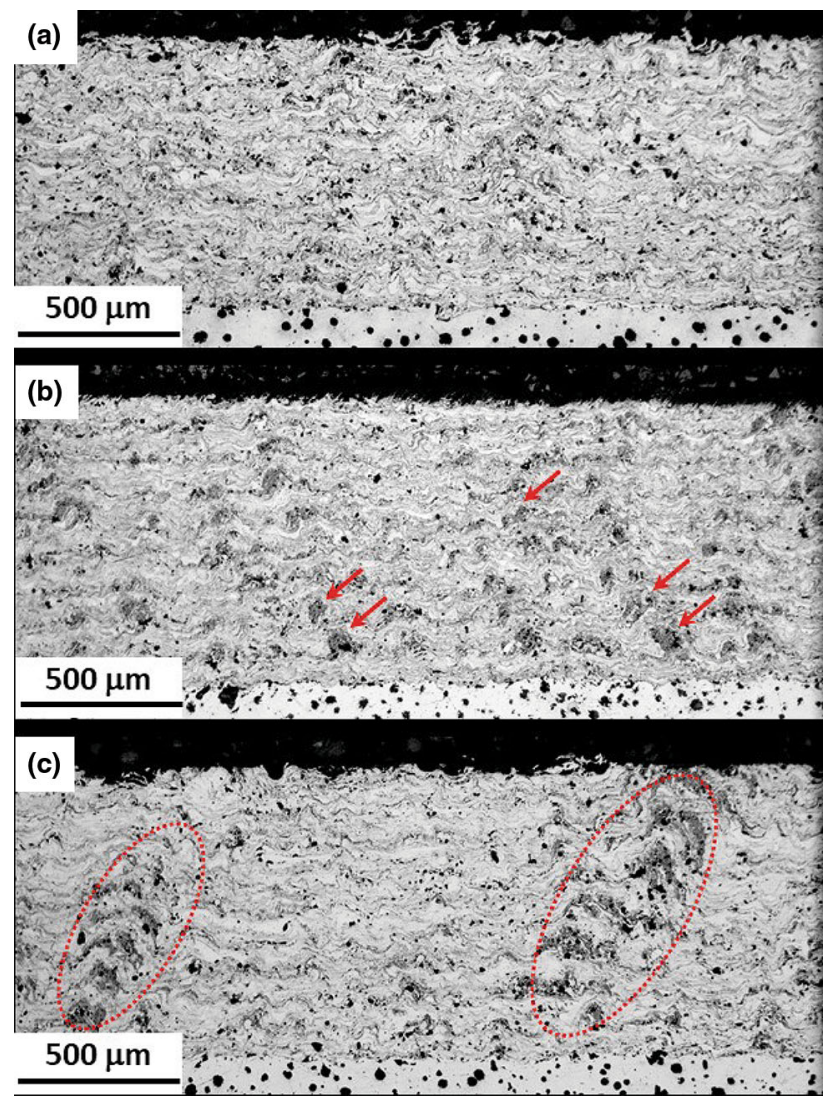

Fig. 5 LOM images of cross sections from: (a) Group 1, (b) Group 2, and (c) Group 3. Annotations highlight areas with elevated oxide content

surface perturbations (Ref 20). This occurs in thicker coatings due to splashing during splat formation. Each droplet that impinges upon the surface generates a number of slower moving, smaller 'splash' droplets that travel radially close to the surface. These droplets are small (high surface area) and slow moving, so they readily oxidize to
$\mathrm{FeO}$; however, because the melting point of $\mathrm{FeO}$ is below that of steel, they contribute to the deposition of splash droplets upon any topological features. Potential features include prior splats or even the leading edge of the previously deposited layer during rastering of the spray. As a result, the liquid $\mathrm{FeO}$ is captured by these features and they grow preferentially to create a diverging cone of high-oxide material $(\operatorname{Ref} 21)$.

The microstructures of the Group1 and Group 2 samples resulted from the same SOD of $150 \mathrm{~mm}$, but different gas pressure, 550 and $825 \mathrm{kPa}$, respectively. The most significant difference based on these processing conditions should be finer droplet size and higher velocity in the Group 2 spray. Since finer particles oxidize faster than coarse ones due to the relatively high surface area, we observe higher oxide in the Group 2 sample. Also, since the droplet velocity is higher in Group 2, we find lower porosity and finer lamellae in that group. Comparing Groups 1 and 3, which were sprayed with the same gas pressure of $550 \mathrm{kPa}$ and different SODs of 150 and $75 \mathrm{~mm}$, respectively, we observe a transition from a relatively uniform lamellar structure in Group 1 to the intermittent high-oxide structure attributed to preferential splatter collection at surface features in Group 3. In this case, the difference in SOD suggests cooler, slower droplets formed the Group 1 microstructure. This appears to be consistent with the higher average porosity in Group 1; however, it seems likely that additional mechanisms are active in developing the Group 3 microstructure. For example, postdeposition oxidation due to the excess heat associated with the shorter SOD likely contributes to the high-oxide structure present in Group 3. While Group 4 was not crosssectioned and examined, it can be reasonably assumed that the combination of high gas pressure and lower SOD would lead to a microstructure with even greater oxide content than is seen in Group 2 or 3. This very high proportion of oxide may have contributed to the failure of Group 4 to produce well-bonded coatings.

Micro-indentation hardness testing revealed a pair of trends in the hardness profiles of the coatings. The coatings in Groups 2 and 3 were harder than those of Group 1, as shown in Fig. 8. This is consistent with the microstructural analysis showing greater oxide content in those groups, and it is well established that oxide content is directly related to coating hardness (Ref 12). Additionally, it is noted that all of the coatings are harder near the surface than near the interface, which is attributed to the additional thermal exposure experienced by the inner layers during the deposition of subsequent layers. The behavior of the Group 3 hardness, with higher values than Group 2 at the interface but lower at the surface, illustrates the complex interplay between the oxide and porosity contents, and their respective distributions within the microstructure. 
Fig. 6 Microstructures of:

(a) Group 1, (b) Group 2,

(c) Group 3-low-oxide, and d)

Group 3-high-oxide.

Annotations highlight areas with elevated oxide content

Fig. 7 Microstructures of:

(a) Group 1, (b) Group 2,

(c) Group 3-low-oxide, and d) Group 3-high-oxide
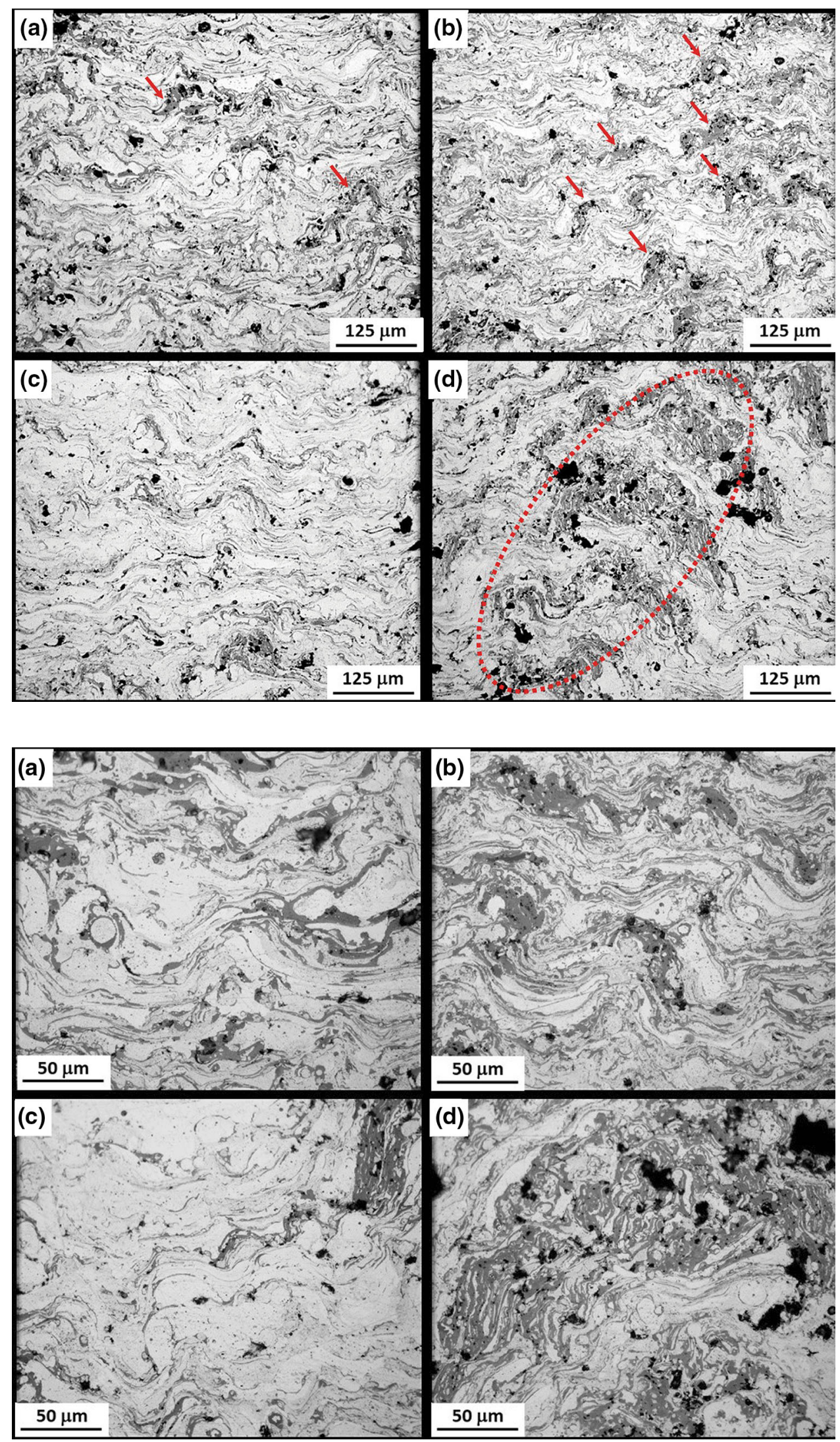


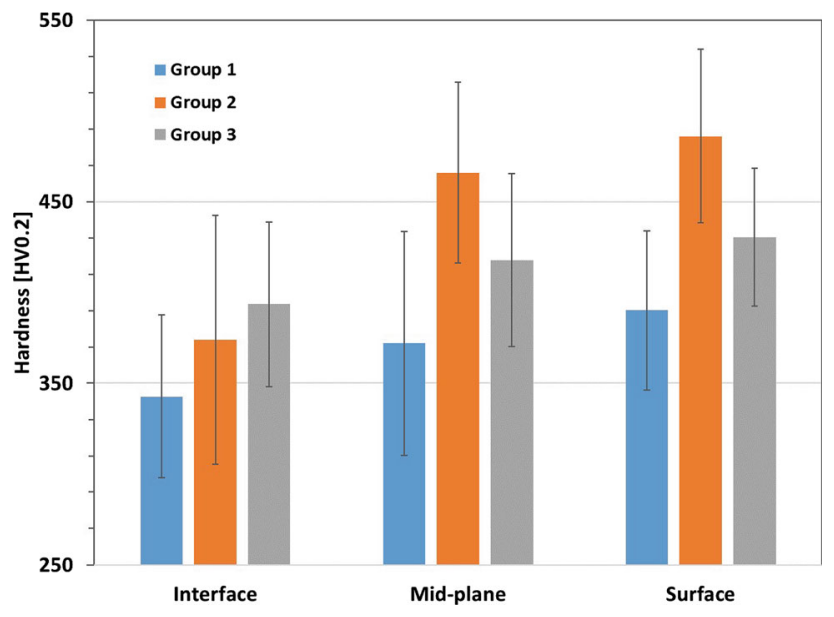

Fig. 8 Micro-indentation hardness results segregated by position in coating. Error bars represent standard deviations

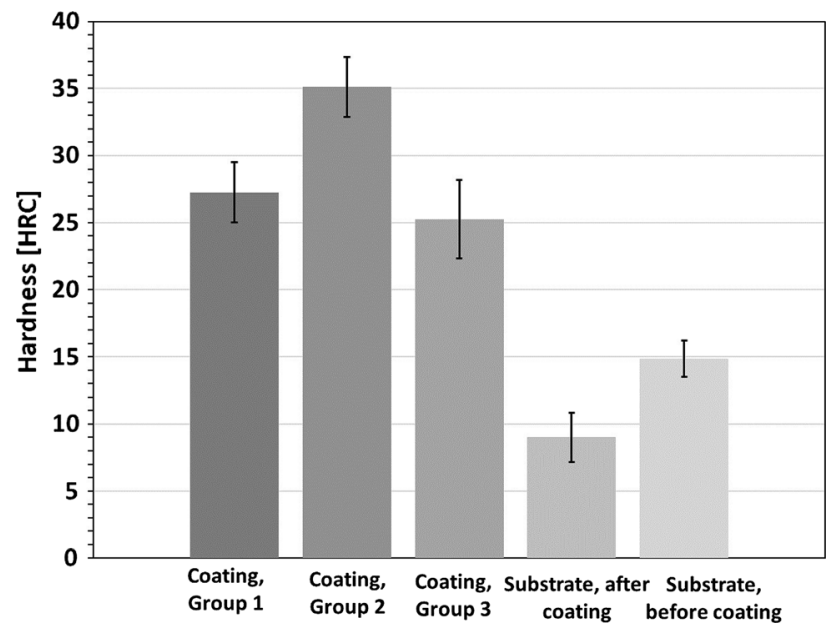

Fig. 9 Rockwell hardness results using Rockwell C test scale

Rockwell $\mathrm{C}$ hardness testing, performed on the external surface of the coatings after sanding, found the highest surface hardness in Group 2 and the lowest in Group 3. This difference from the micro-indentation hardness result is attributable to the different test geometries and indenter sizes. The high hardness in Group 2 is explained by the increased oxide content and is consistent with the general trend of high pressure leading to increased hardness. The lower hardness of Group 3 relative to Groups 1 and 2 is attributed to the large regions of high porosity present in Group 3. In addition, the hardness of the ductile iron substrate was tested both pre- and post-coating. The results, Fig. 9, show that the ductile iron substrate is substantially softened by the thermal history associated with the coating process. All of the coatings were harder than the substrate, with the virgin substrate averaging $15 \mathrm{HRC}$ and the baseline coating averaging $27 \mathrm{HRC}$. The hardness of the virgin substrate agrees well with published values, although it is noted that Rockwell $\mathrm{C}$ values less than 20 are outside the ideal range for that hardness scale (Ref 22). The softening of the substrate during the coating process indicates that the ductile iron is being annealed by the heat introduced during the coating process. This has important implications for the mechanical properties of a coated system, as an annealed substrate will possess lower strength and higher ductility than an equivalent as-cast part.

\section{Bend Testing}

The first phase of bend testing sought to obtain an understanding of how the elastic modulus of the 420 stainless steel TWA coating compares to the modulus of the substrate. Similar methodologies have been employed by Leither et al. (Ref 13) and You et al. (Ref 23) to calculate the elastic moduli of thermal spray coatings. Here, the bending displacements were limited to the elastic regime in order to avoid the complications associated with plasticity. The samples comprised substrates $9.5 \mathrm{~mm}$ thick that were coated using the conditions described for Groups 1, 2 and 3 in Table 2. Samples are referred to by their group number and sample number (ex: sample 1-2 indicates sample 2 from Group 1). Uncoated substrates were tested first to confirm the substrate elastic modulus, $\mathrm{E}_{\mathrm{a}}$. The ductile iron substrate was found to have an elastic modulus of $161 \mathrm{GPa}$ and in good agreement with published values (159-176 GPa) (Ref 22).

The elastic moduli of the coatings were calculated from bend test results for the coated substrates using the equivalent width method for bending of a composite beam as the basis for the analysis (Ref 24). This method transforms the physical system of a beam with two sections of equal width and differing moduli to a system of two sections of equal moduli and differing width. This transformation is represented in Fig. 10, where

$w_{b}=w *\left(\frac{E_{b}}{E_{a}}\right)$

with $w$ as the width of the sample and $\mathrm{w}_{\mathrm{b}}$ as the equivalent width of the coating. The neutral axis of the system is calculated to be located at

$\bar{y}=\frac{w t_{a}\left(t_{b}+\frac{t_{a}}{2}\right)+w_{b} t_{b}\left(\frac{t_{b}}{2}\right)}{w t_{a}+w_{b} t_{b}}$

where $t_{a}$ is the substrate thickness, $t_{b}$ is the coating thickness, and $\bar{y}$ is the position of the neutral axis. Use of the parallel axis theorem finds that the second moment of the beam, $I_{x}$, is found by 
Fig. 10 Schematic of equivalent width method
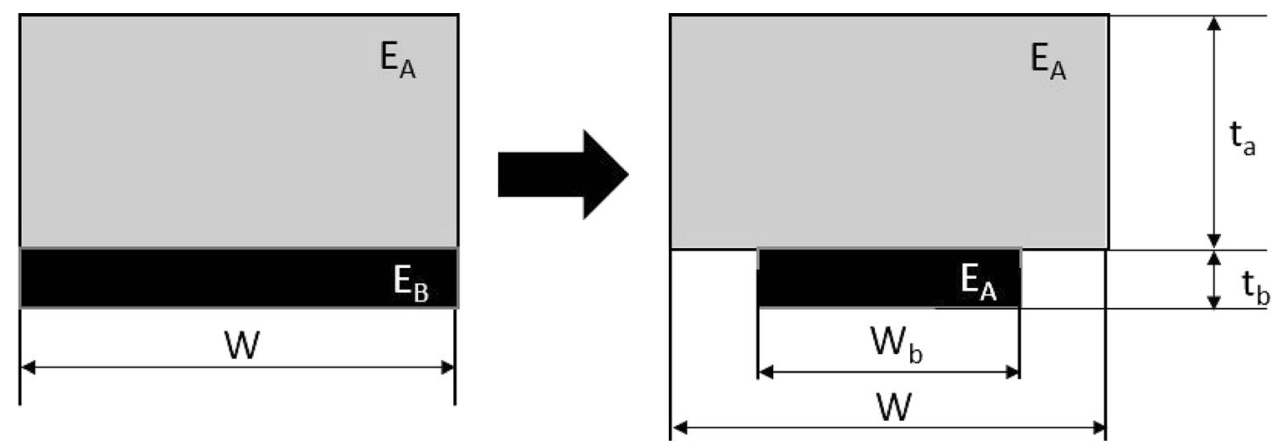

$$
\begin{aligned}
I_{x}= & \frac{w t_{a}^{3}}{12}+w t_{a}\left(t_{b}+\frac{t_{a}}{2}-\bar{y}\right)^{2} \\
& +\frac{w_{b} t_{b}^{3}}{12}+w_{b} t_{b}\left(\bar{y}-\frac{t_{b}}{2}\right)^{2}
\end{aligned}
$$

Finally, the relationship between the load and deflection of a beam undergoing three point bending is known to be

$\delta=\frac{\mathrm{FL}^{3}}{48 \mathrm{EI}_{\mathrm{eq}}}$

where

$E I_{e q}=E_{a} I_{x}$

and $\mathrm{F}$ is the applied load, $\mathrm{L}$ is the distance between the supports, and $\delta$ is the beam deflection.

This system of equations is not analytically solvable for $E_{b}$, but numerical solution allows for calculation of the coating modulus given the geometry of the specimen and the load-displacement relationship. In order to minimize the effect of experimental scatter on the convergence of the numerical solution, the slope of the load-displacement curve (determined from a best fit using a nonlinear least squared regression analysis) was used as the input to the calculations.

The analysis was performed on load-displacement data from a series of three specimens per coating group. Calculated strains were compared with data from an experiment that included a strain gauge monitored with a quarter bridge arrangement using an excitation voltage of $2.5 \mathrm{~V}$ and a gage factor of 2.04 (Group 1-Sample 2). The strain gauge was affixed to the coated side of the specimen, and strains were recorded through the elastic region. For comparison to the initial test data, the measured strains were converted to displacement by the following relation

$\delta=\frac{\in L^{2}}{6 t}$

which assumes that the beam flexes uniformly. The displacements calculated from the strain gauge data were compared to the raw displacement data to determine a correction factor to account for localized deformation at the supports.
Table 3 Average elastic modulus, failure stress, and failure strain for each bend testing group

\begin{tabular}{lccc}
\hline Group & Calculated $\mathrm{E}_{\mathrm{B}}, \mathrm{GPa}$ & $\sigma_{\text {в }}$ at failure, MPa & ЕВ at failure, - \\
\hline 1 & 152 & 349 & 0.0027 \\
2 & 83 & 259 & 0.0029 \\
3 & 110 & 308 & 0.0031 \\
\hline
\end{tabular}

The results of the calculations are given in Table 3. The average calculated coating modulus for Group 1 indicates that the coating can achieve a comparable elastic modulus to the substrate. However, the results from Groups 2 and 3 are significantly lower, with the modulus found for Group 2 only $51 \%$ that of the substrate. Comparison of the microstructures discussed above and the elastic moduli indicates that increased material homogeneity (reduction in porosity and oxide) is linked to an increased elastic modulus. Group 1 is the group with the lowest oxide content and was found to have the stiffest modulus. Conversely, Group 2 possesses the largest quantity of material defects interspersed through the microstructure and displayed by far the lowest elastic modulus. These results are consistent with past works which find the elastic modulus of TWA materials to be lower than that of the bulk material, as 420 stainless steel has an elastic modulus in the range of 200 GPa or $31 \%$ stiffer than the Group 1 coatings (Ref 12, 13).

These findings have significant design implications because the distribution of stress between the coating and substrate is dependent on the ratio of the respective elastic moduli. As such, any assessment of the suitability of a TWA coating in a structural application must include both determination of the coating elastic modulus and detailed calculations of the coating stress. These calculations should not be based on the assumption that the coating is stressed as though it is simply an extension of the substrate or with properties identical to the bulk coating material (Ref 9).

The second phase of bend testing assessed the failure behavior of the coatings. In this phase, the load was increased until there was either: (a) a clear discontinuity in 
the load-displacement curve, or (b) an audible cracking of the coating, or (c) both conditions occurring simultaneously (most common). Representative load-displacement curves are shown in Fig. 11 for each group. In all cases, the curves exhibit a clear discontinuity, which represents the load at which the coating failed. Samples $1-3$ and 3-2 show 'typical' behavior for an as-sprayed coating, failing at a high load with single transverse crack in the center of the span, as well as interfacial cracking. All samples had extensive interfacial cracking (to be discussed below). The presence of only a single discontinuity in the load-displacement curves suggests that the interfacial cracking consistently occurs near the same time or simultaneously as the transverse failures. This can be explained by a release of the elastic energy stored in the coating at the moment of coating fracture, which breaks the adhesive bond in the vicinity of the point of coating failure.

Using the substrate and coating elastic moduli calculated above, the maximum stresses in both the substrate and coating were calculated from

$\sigma_{a}=\frac{M\left(t_{a}+t_{b}-\bar{y}\right)}{I_{x}}$

and

$\sigma_{b}=\frac{M \bar{y}}{I_{x}}\left(\frac{E_{b}}{E_{a}}\right)$

The average failure stress and strain of each group are provided in Table 3. The average maximum stress in the coatings was an order of magnitude greater than the adhesive strength reported above for all groups, with Group 1 displaying the greatest in-plane strength. Stress and strain of a representative coating of each group are plotted in Fig. 12. The low failure strain values, an order of magnitude less than those of the ductile iron substrate or bulk 420 stainless steel, are another major difference that must be considered when designing a coated system. This brittle nature of twin wire arc coatings is consistent with past works and is attributed to the oxide content of the coatings (Ref 4).

It should be noted that once the coating fails, the stress in the substrate becomes

$\sigma_{a}=\frac{M\left(\frac{t_{a}}{2}\right)}{I_{a}}$

As a result, the substrate stress suddenly changes when the coating fails, rapidly increasing to a higher value because the coating fails to bear any load once fractured. The significance of this effect depends on the ratio of coating to substrate thickness and is more pronounced in systems where the coating consists of a large portion of the overall system thickness. This is another critical aspect to consider when designing a coated system to ensure a coating failure does not cascade into further failure of the substrate material.

\section{Fractography}

After bend testing, selected samples were sectioned for metallography and fractography. Fig. 13(a) shows a plane view of the primary transverse crack that resulted in final fracture of the coating in Sample 1-3. The yellow line in Fig. 13 indicates the center of the span, and thus the expected location of the maximum tensile stress at the surface of the coating. It is interesting to note that the crack, which runs from edge to edge and is approximately perpendicular to the long axis of the sample, deviates from the line of maximum stress near the right side of the image. This indicates the presence of a local stress concentrator, or conversely a region of defective coating, that caused the
Fig. 11 Representative loaddisplacement curves for selected 3-point bend tests

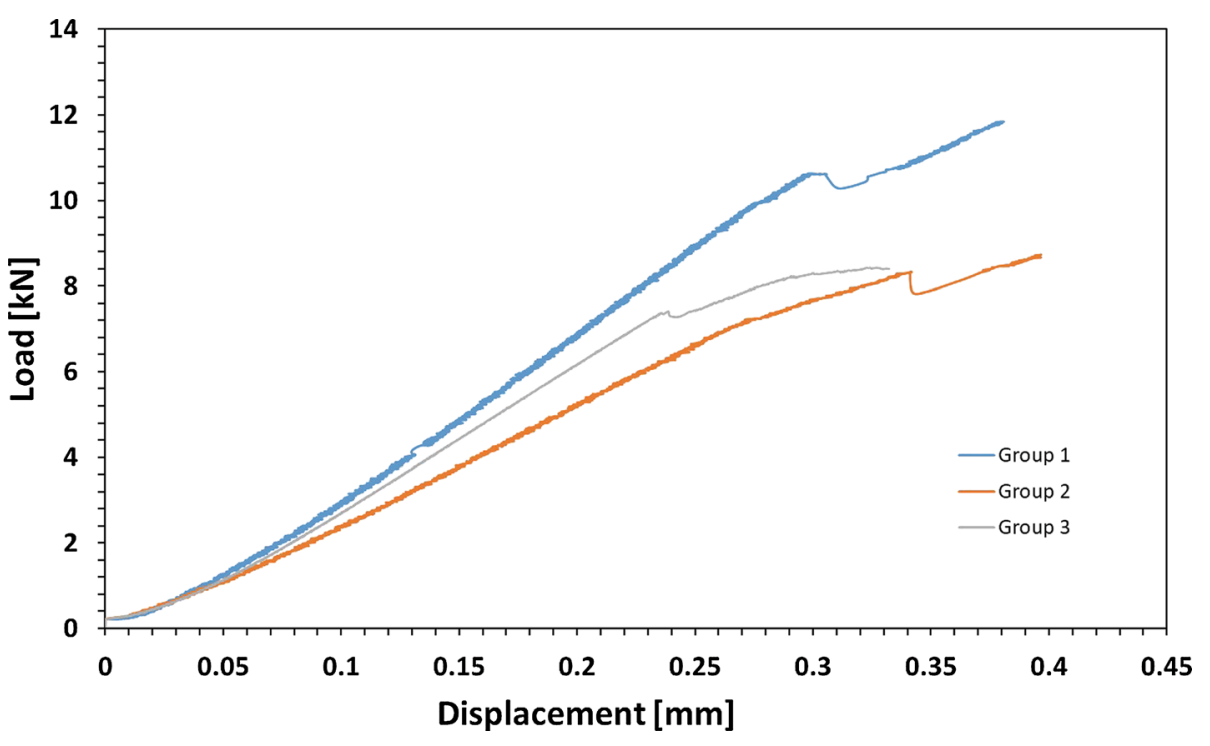


Fig. 12 Calculated stress-strain curves for a representative sample from each bending group

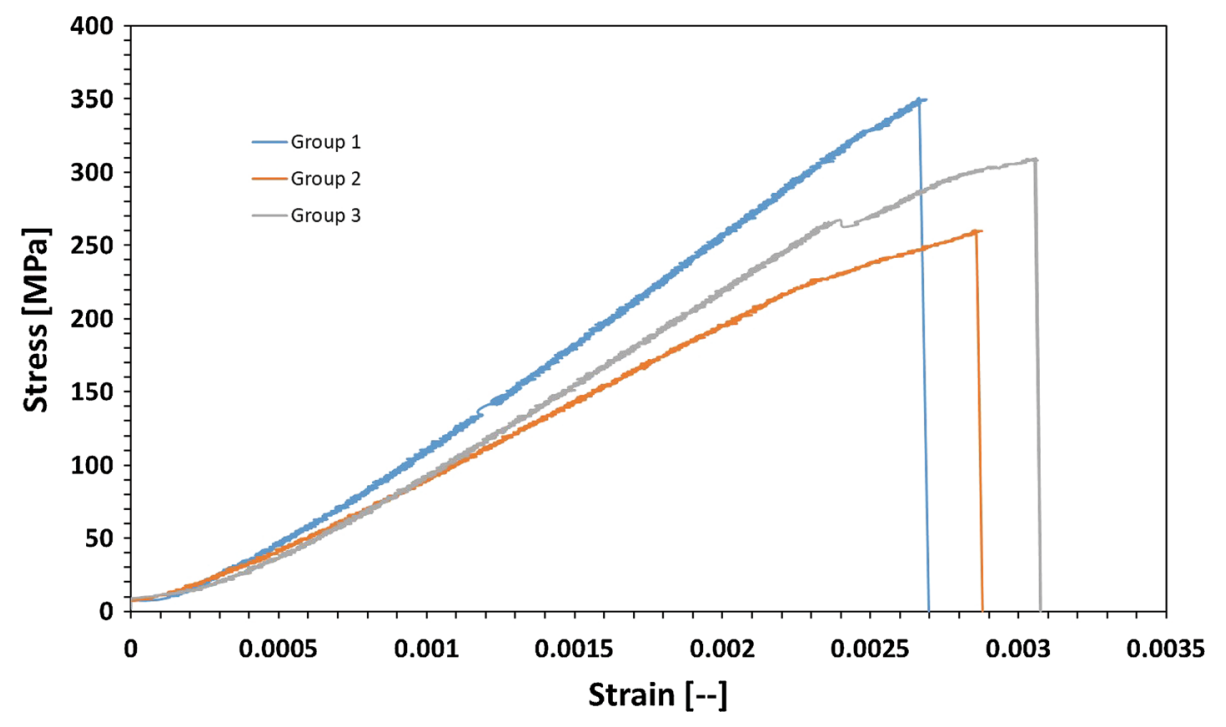

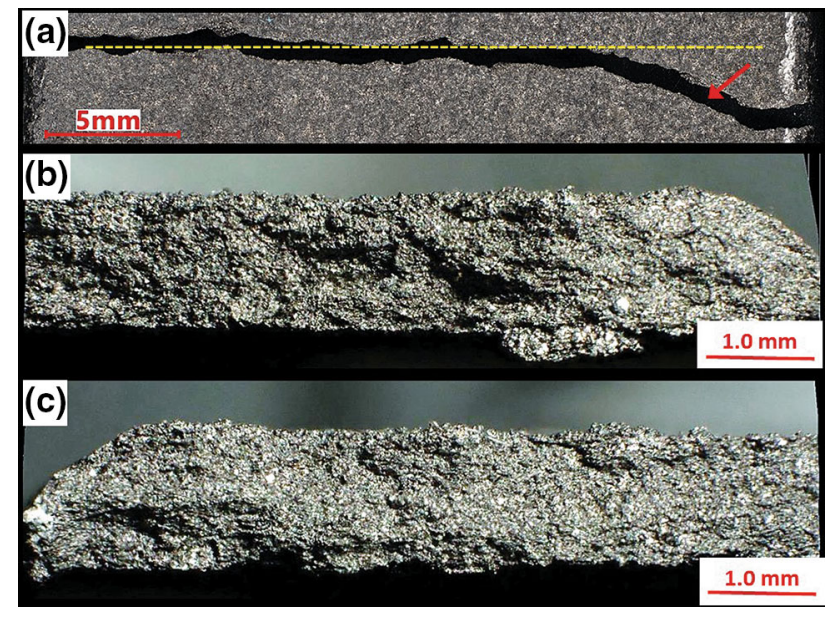

Fig. 13 Fracture surface from bending sample 1-3: (a) Top surface of the coating at the point of failure, $(b, c)$ left and right ends of the upper fracture surface from (a). The yellow line indicates the center of the span, and thus the expected location of the maximum tensile stress at the surface of the coating

crack to initiate near the right side of the image before the coating strength was exceeded at the expected maximum stress location (yellow line). Fig. 13(b) and (c) shows the right and left ends, respectively, of the fracture surface from the top-side of Fig. 13(a). The actual fracture surfaces are smoother near the ends, probably indicating fast fracture at those locations. In the angled section of the fracture, near the arrow in Fig. 13a, the surface is significantly rougher, with more than one feature deep enough to cast a shadow in the image. This indicates stable crack propagation, possibly with multiple initiation sites in that region of the coating. Fig. 14 shows LOM images of polished metallurgical cross sections of the primary transverse cracks from Sample 2-2 (Fig. 14a-c) and Sample 1-1 (Fig. 14d-f). The views are transverse to the long axis of the samples such that the long axis of the samples runs leftto-right in the images. The images show crack geometries that are characterized by an irregular crack path, and a tendency to deviate at a high angle (from normal) in the lower third of the coating. Fig. 15 shows metallurgical cross sections of the interface cracks that were present across the entire cross section in both samples. These fractures are adhesive in nature, with the film pulling away from the substrate in most locations.

\section{Wear Testing}

The results of the wear testing are given in Fig. 16. The average wear volume from each group is plotted with the error bars showing the minimum and maximum measurements. It is clear from Fig. 16 that the TWA coatings underwent greater volume loss than the ductile iron substrate. Because wear resistance is inversely related to volume loss, this implies that the TWA coatings possess poorer wear resistance than the uncoated substrate. Representative images of the wear scars are presented in Fig. 17. The uncoated substrates wore the least with an average wear volume of $1.36 \mathrm{~mm}^{3}$. Samples from Group 1 possessed the best wear resistance of the coated specimens, with an average wear volume of $1.56 \mathrm{~mm}^{3}$ or $15 \%$ greater than the uncoated substrate, while Group 2 possessed the worst wear resistance with an average of $1.78 \mathrm{~mm}^{3}$ or $31 \%$ greater than the substrate. This result is somewhat unexpected, as Group 1 was measured as softer than Groups 2 and 3 and abrasive wear resistance is often directly linked to hardness (Ref 25). The difference in microstructure is certainly an important factor, with Group 1 displaying the lowest oxide content. Similarly, the observation that all coatings possessed worse wear resistance than the uncoated substrate, despite the substrate being substantially softer 
Fig. 14 Cross sections of the fracture surfaces from: $(a, b, c)$ bend sample 2-2 and (d,e,f) bend sample 1-1. Arrows highlight interfacial cracking
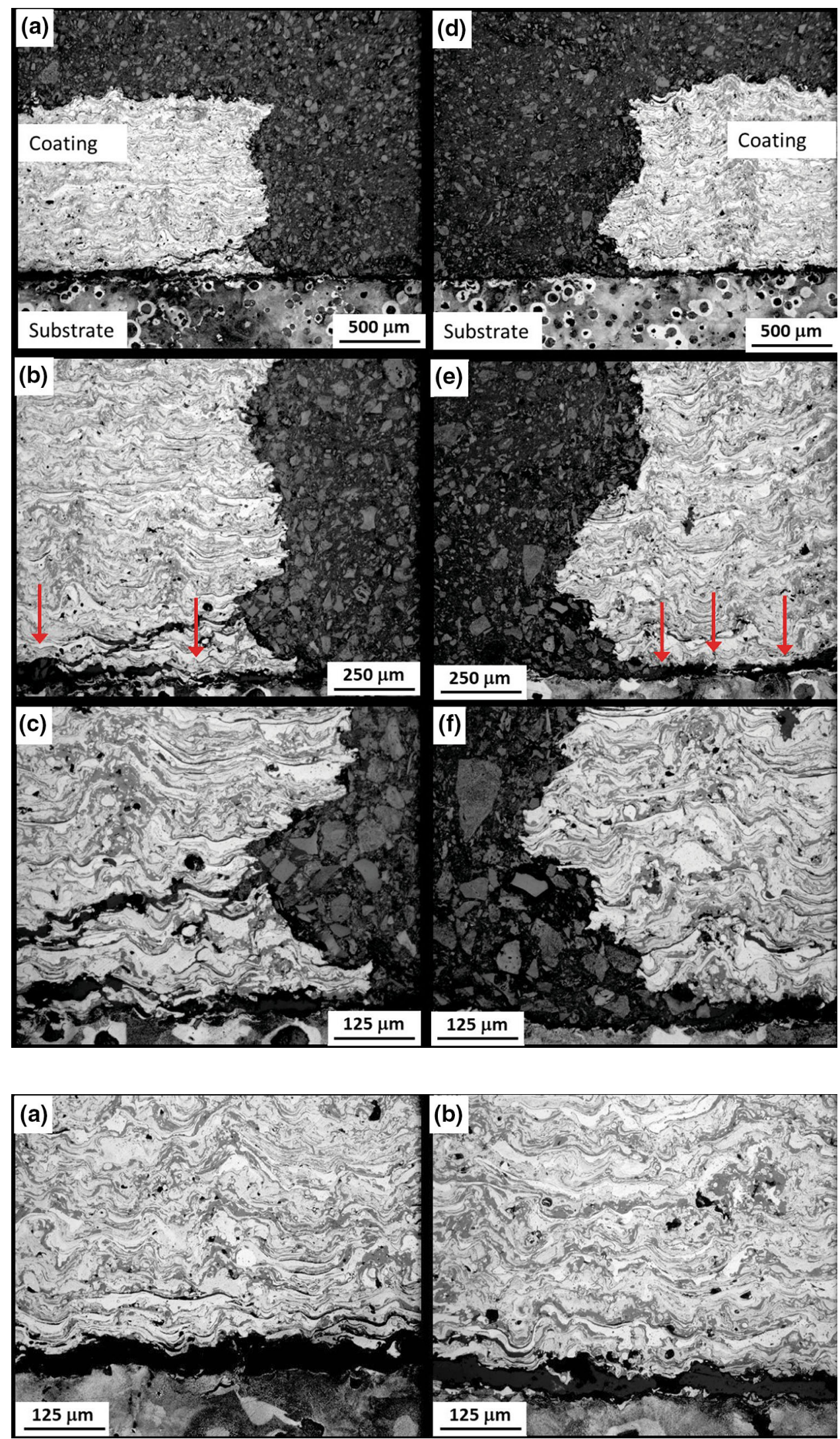

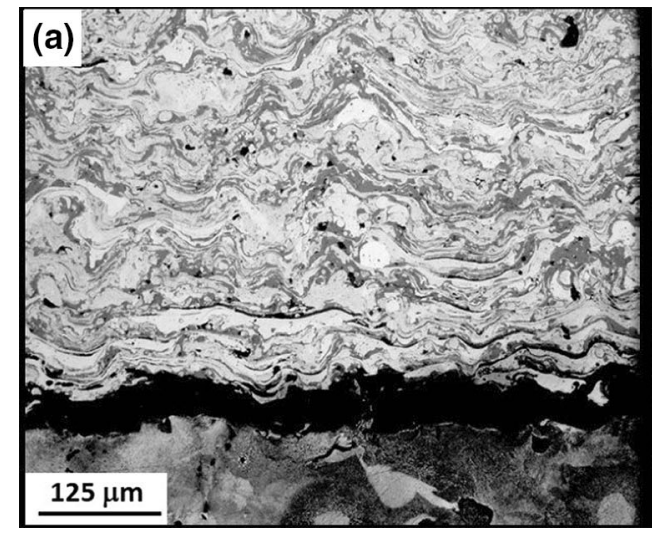

$125 \mu \mathrm{m}$
Fig. 15 Interface fractures in (a) sample 2-2, and (b) sample 1-1

\section{.}


than the coatings, furthers the hypothesis that the porosity and oxide content of the coatings are key factors which drive the material loss. The complex interplay between the coating constituents, relatively soft alloy and hard oxide, is apparent with this wear behavior. One possible mechanism for the higher wear rate observed in the higher oxide content coatings is pull-out of the oxide particles. These oxide particles may then become entrapped and act as an additional abrasive, causing additional wear. The absence of this mechanism with the ductile iron substrates can also explain the difference in wear resistance between the substrates and the coatings. These observations regarding the abrasive wear of TWA coatings are consistent with the findings of Cooke et al. (Ref 26).

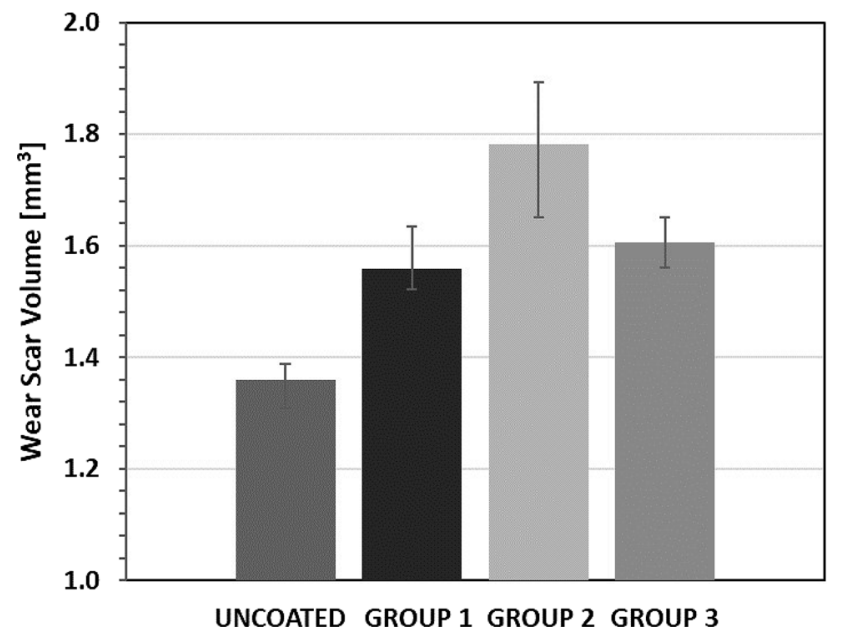

Fig. 16 ASTM G174 abrasive wear test results

\section{Summary and Conclusions}

The results presented above indicate that the hardness, microstructure, and adhesive strength of TWA-coated 420 stainless steel on ductile iron can be significantly affected by the SOD and gas pressure during deposition. The results show that samples produced with either increased gas pressure or decreased SOD exhibited elevated adhesive strength and coating hardness. However, the combination of increased gas pressure and decreased SOD resulted in a disbonded coating with no adhesive strength, likely due to excessive oxide formation. The observed changes in mechanical properties appear to correlate to microstructural changes that relate to the oxide content, porosity content, and mixing of the phases, though a larger sample size would be needed to confirm these relationships. Bend testing yielded an average in-plane moduli ranging from 51 to $95 \%$ of the substrate modulus, depending on spray conditions, and average strength of the coating ranging from 259 to $349 \mathrm{MPa}$.

These observations have important implications when assessing the suitability of TWA coatings for structural applications. One significant observation is that TWA coatings can withstand significantly higher tensile loads inplane (bending) than normal to the coating interface, on the order of 10x. In addition, the average failure stress, 349 $\mathrm{MPa}$, is far closer to the tensile strength of bulk 420 steel, reported to be $655 \mathrm{MPa}$, than the adhesive strength of the coatings. Wear testing results indicate that TWA coatings such as the ones studied in this paper are viable in ductile cast iron wear applications, although designers should be aware of the moderately reduced wear resistance relative to
Fig. 17 Selected abrasive wear scar images. (a) Uncoated ductile iron substrate (b) Sample 3-2
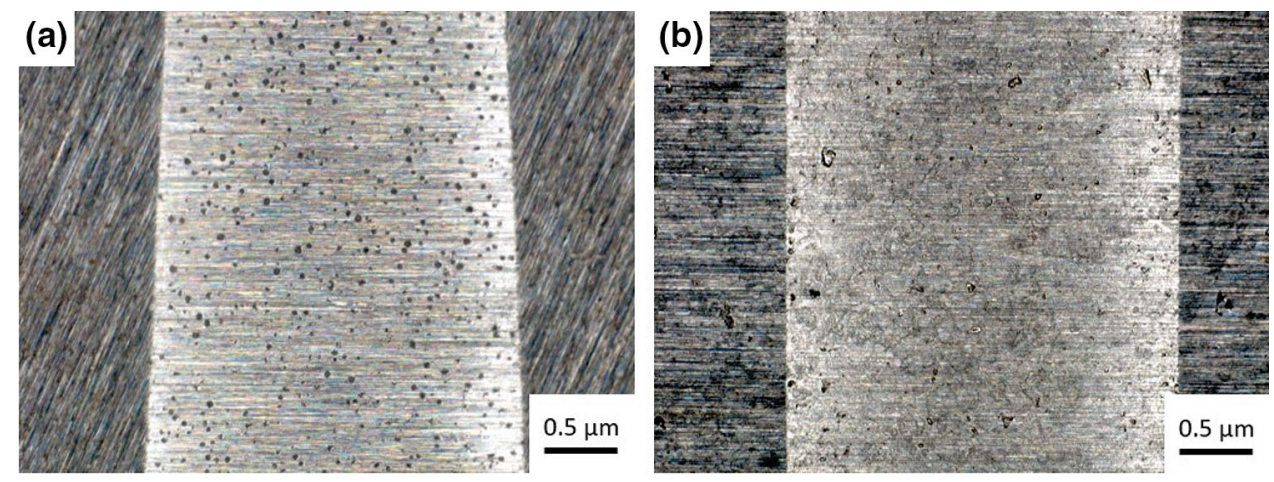
the ductile iron substrate. Future testing will expand on the wear testing and seek to better characterize the wear mechanisms of the TWA coatings and how they compare to those of the ductile iron substrate.

Acknowledgments The authors would like to thank Domenic Maiola, Jason Purvee, and Mitch Campbell for their important contributions to this research. This material is based upon work supported by the Office of Naval Research under Award No. N00014-18-12339. Disclaimer - Any opinions, findings, and conclusions or recommendations expressed in this material are those of the author(s) and do not necessarily reflect the views of the Office of Naval Research.

\section{References}

1. I. Gedzevicius and A.V. Valiulis, Analysis of Wire Arc Spraying Process Variables on Coatings Properties, J. Mater. Process. Technol., 2006, 175(1-3), p 206-211. https://doi.org/10.1016/j. jmatprotec.2005.04.019

2. D. Poirier et al., Performance Assessment of Protective Thermal Spray Coatings for Lightweight Al Brake Rotor Disks, J. Therm. Spray Technol., 2019, 28, p 291-304.

3. E.A. Esfahani, H. Salimijazi, M. Golozar, J. Mostaghimi and L. Pershin, Study of Corrosion Behavior of Arc Spraying Aluminum Coating on Mild Steel, J. Therm. Spray Technol., 2012, 21(6), p 1195-1202.

4. G. Burkle, H.J. Fecht, A. Sagel and C. Wanke, Dynamic mechanical analysis of the mechanical properties of Al- and Febased thermal spray coatings, Thermal Spray: New Surfaces for a New Millenium. C.C. Berndt, K.A. Khor, E.F. Lugscheider Ed., Ohio, ASM International, 2001, p 999-1002

5. J. Wang, J. Liu, L. Zhang, J. Sun and Z. Wang, Microstructure and Mechanical Properties of Twin-Wire Arc Sprayed Ni-Al Composite Coatings on 6061-T6 Aluminum Alloy Sheet, Int. J. Miner. Metall. Mater., 2014, 21(5), p 469-478.

6. T.C. Chen, C.C. Chou, T.Y. Yung, K.C. Tsai and J.Y. Huang, Wear Behavior of Thermally Sprayed $\mathrm{Zn} / 15 \mathrm{Al}, \mathrm{Al}$ and Inconel 625 Coatings on Carbon Steel, Surf. Coatings Technol., 2016, 303, p 78-85. https://doi.org/10.1016/j.surfcoat.2016.03.095

7. S. Sampath, X.Y. Jiang, J. Matejicek, L. Prchlik, A. Kulkarni and A. Vaidya, Role of Thermal Spray Processing Method on the Microstructure, Residual Stress and Properties of Coatings: An Integrated Study of Ni-5 wt. \% Al Bond Coats, Mater. Sci. Eng. A, 2004, 364(1-2), p 216-231. https://doi.org/10.1016/j.msea. 2003.08.023

8. G.M. Smith and S. Sampath, Sustainability of Metal Structures via Spray-Clad Remanufacturing, Jom, 2018, 70(4), p 512-520. https://doi.org/10.1007/s11837-017-2676-0

9. A. Purniawan, D. A. K. Hapsari, and H. Purwaningsih, Deposition and post heat treatment of ni-Al/Ni-20Cr on AISI 4140 using twin wire arc spray method. In: AIP Conference Proceedings (Vol. 2262, No. 1, p. 060008), https://doi.org/10.1063/5. 0015688.

10. D.F. Fitriyana et al., The Effect of Compressed Air Pressure and Stand-off Distance on the Twin Wire Arc Spray (TWAS) Coating for Pump Impeller from AISI 304 Stainless Steel, NAC, 2019, 2020, p 119-130.

11. M.P. Planche, H. Lioa and C. Coddet, Relationships Between Inflight Particle Characteristics and Coating Microstructure with a
Twin Wire Arc Spray Process and Different Working Conditions, Surf. Coatings Technol., 2004, 182, p 215-226.

12. G. Jandin, H. Liao, Z.Q. Feng and C. Coddet, Correlations Between Operating Conditions, Microstructure and Mechanical Properties of Twin Wire Arc Sprayed Steel Coatings, Mater. Sci. Eng. A, 2003, 349(1-2), p 298-305. https://doi.org/10.1016/ S0921-5093(02)00767-0

13. C. Leither, J. Risan, M. Bashirzadeh and F. Azarmi, Determination of the Elastic Modulus of Wire Arc Sprayed Alloy 625 using Experimental, Analytical, and Numerical Simulations, Surf. Coatings Technol., 2013, 235, p 611-619. https://doi.org/10. 1016/j.surfcoat.2013.08.033

14. E. Rodriguez, M.A. González, H.R. Monjardín, O. Jimenez, M. Flores and J. Ibarra, Heat Treated Twin Wire Arc Spray AISI 420 Coatings under Dry and Wet Abrasive Wear, Met. Mater. Int., 2017, 23(6), p 1121-1132. https://doi.org/10.1007/s12540-0176398-1

15. F.N. Longo, Coating processing, Handbook of Thermal Spray Technology. J.R. Davis Ed., ASM International, Ohio, 2004

16. ASTM, "D-4541-17: Standard Test Method for Pull-Off Strength of Coatings Using Portable Adhesion Testers." ASTM International, West Conshohocken, PA, pp. 1-16, 2017, doi: https://doi. org/10.1520/D4541-17.2

17. ASTM, "E-2109-01 Standard Test Methods for Determining Area Percentage Porosity in Thermal Sprayed Coatings," vol. 01, no. Reapproved. ASTM International, West Conshohocken, PA, 2014, doi: https://doi.org/10.1520/E2109-01R14.2

18. ASTM, "E-18-20: Standard Test Methods for Rockwell Hardness of Metallic Materials." ASTM International, West Conshohocken, PA, pp. 1-38, 2020, doi: https://doi.org/10.1520/ E0018-14.2

19. ASTM, "G-174-17: Standard Test Method for Measuring Abrasion Resistance of Materials by Abrasive Loop Contact," vol. i, no. Reapproved. ASTM International, West Conshohocken, PA, pp. 1-7, 2017, doi: https://doi.org/10.1520/G0174-04R17.2

20. A.P. Newbery and P.S. Grant, Oxidation during Electric Arc Spray Forming of Steel, J. Mater. Process. Technol., 2006, 178(1-3), p 259-269. https://doi.org/10.1016/j.jmatprotec.2006. 03.176

21. S. Hoile, T. Rayment, P.S. Grant and A.D. Roche, Oxide Formation in the Sprayform Tool Process, Mater. Sci. Eng. A, 2004, 383(1), p 50-57. https://doi.org/10.1016/j.msea.2004.02.068

22. D. Stefanescu, Ed., "Mechanical Properties of Ductile Irons," in ASM Handbook, Volume 1A, Cast Iron Science and Technology, vol. 15, no. c, ASM International, 2018, pp. 456-471

23. J.H. You, T. Höschen and S. Lindig, Determination of Elastic Modulus and Residual Stress of Plasma-Sprayed Tungsten Coating on Steel Substrate, J. Nucl. Mater., 2006, 348(1-2), p 94-101. https://doi.org/10.1016/j.jnucmat.2005.09.015

24. W. C. Young and R. G. Budynas, Roark's Formulas for Stress and Strain. 1989

25. J. Rendón and M. Olsson, Abrasive Wear Resistance of some Commercial Abrasion Resistant Steels Evaluated by Laboratory Test Methods, Wear, 2009, 267(11), p 2055-2061. https://doi.org/ 10.1016/j.wear.2009.08.005

26. K. Cooke, G. Oliver, V. Buchanan and N. Palmer, Optimisation of the Electric Wire Arc-Spraying Process for Improved Wear Resistance of Sugar Mill Roller Shells, Surf. Coat. Technol., 2007, 202, p 185-188.

Publisher's Note Springer Nature remains neutral with regard to jurisdictional claims in published maps and institutional affiliations. 